\title{
Directed Assembly and Development of Material-Free Tissues with Complex Architectures
}

Citation for published version (APA):

Vrij, E., Rouwkema, J., LaPointe, V., van Blitterswijk, C., Truckenmuller, R., \& Rivron, N. (2016). Directed Assembly and Development of Material-Free Tissues with Complex Architectures. Advanced Materials, 28(21), 4032-4039. https://doi.org/10.1002/adma.201505723

Document status and date:

Published: 01/06/2016

DOI:

10.1002/adma.201505723

Document Version:

Publisher's PDF, also known as Version of record

Document license:

Taverne

Please check the document version of this publication:

- A submitted manuscript is the version of the article upon submission and before peer-review. There can be important differences between the submitted version and the official published version of record.

People interested in the research are advised to contact the author for the final version of the publication, or visit the DOI to the publisher's website.

- The final author version and the galley proof are versions of the publication after peer review.

- The final published version features the final layout of the paper including the volume, issue and page numbers.

Link to publication

\footnotetext{
General rights rights.

- You may freely distribute the URL identifying the publication in the public portal. please follow below link for the End User Agreement:

www.umlib.nl/taverne-license

Take down policy

If you believe that this document breaches copyright please contact us at:

repository@maastrichtuniversity.nl

providing details and we will investigate your claim.
}

Copyright and moral rights for the publications made accessible in the public portal are retained by the authors and/or other copyright owners and it is a condition of accessing publications that users recognise and abide by the legal requirements associated with these

- Users may download and print one copy of any publication from the public portal for the purpose of private study or research.

- You may not further distribute the material or use it for any profit-making activity or commercial gain

If the publication is distributed under the terms of Article $25 \mathrm{fa}$ of the Dutch Copyright Act, indicated by the "Taverne" license above, 


\title{
Directed Assembly and Development of Material-Free Tissues with Complex Architectures
}

\author{
Erik Vrij, Jeroen Rouwkema, Vanessa LaPointe, Clemens van Blitterswijk, \\ Roman Truckenmüller, and Nicolas Rivron**
}

A long-sought goal in the field of regenerative medicine is the elaboration of scalable methods to assemble and direct the development of complex tissues for the use as models and as implants. Often, engineered tissues are constrained by supporting scaffolds and unable to naturally develop their architecture, which impairs their functionality. ${ }^{[1,2]}$ Here, we demonstrate an accessible and scalable bottom-up method to build complex 3D tissues up to the centimeter scale using only cells as a building material. Tissues are fabricated through essential steps of cellular building block formation and directed differentiation on a platform compatible with high-content screening. By this method of sequential directed assembly, tissues contract, deform, and change their shape stereotypically; they develop a primitive vasculature and stabilize themselves through self-scaffolding. As an example, we demonstrate the formation of a tissue resembling the small bone from the inner-ear with unprecedented detail.

Tissues generated in vitro are of interest to the field of regenerative medicine to replace lost, damaged, or diseased tissues, model diseases, and support the development of drugs. Classically, engineered tissues are formed via a combination of cells and structurally supporting scaffolds, often made of biodegradable polymers or hydrogels. The great potential of using scaffolds lies in the freedom of geometrical design, thus yielding constructs of clinically relevant sizes and shapes. However, the biological complexity of in vitro-generated tissues is still limited. Central to this problem is that tissue development is crucially dependent on the initial 3D architecture of the tissue and on its ability to freely remodel and deform. ${ }^{[1,3]}$ Currently, bottom-up tissue engineering is emerging as a methodology to

\author{
E. Vrij, Dr. V. LaPointe, Prof. C. van Blitterswijk, \\ Dr. R. Truckenmüller, Dr. N. Rivron \\ Department of Complex Tissue Regeneration \\ MERLN Institute for Technology-Inspired \\ Regenerative Medicine \\ Maastricht University \\ Universiteitssingel 40, 6229 ER \\ Maastricht, The Netherlands \\ E-mail: nicolasrivron@gmail.com \\ Dr. J. Rouwkema \\ Department of Biomechanical Engineering \\ MIRA Institute for Biomedical Technology and Technical Medicine \\ University of Twente \\ Drienerlolaan 5, 7522 NB, Enschede, The Netherlands \\ Dr. N. Rivron \\ Hubrecht Institute for Developmental Biology and Stem Cell Research \\ Uppsalalaan 8, 3584 CT, Utrecht, The Netherlands

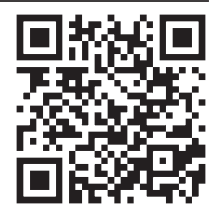

DOI: 10.1002/adma.201505723 increase the complexity of tissues (reviewed in refs. ${ }^{[4,5]}$ ). Generally, bottom-up strategies attempt in building tissues by the self-assembly or directed assembly of cellular modules, which permits increased spatial and temporal control over the tissue architecture. ${ }^{[5]}$ Using such a bottom-up approach it is envisioned that the hierarchical structure of tissues is more akin to native tissues than using a classical top-down approach. Hereto, a crucial aspect is that the tissue building blocks support integration (establishment of cell junctions), structural deformation, and morphogenesis of the tissue after assembly.

Bottom-up approaches often use building blocks combining cells and materials to provide bio functional cues and provisional mechanical support. A popular approach is the use of gel-like materials in which cells or aggregates of cells are embedded. For example, using 3D bioprinting ${ }^{[6]}$ or topographic molding, ${ }^{[7]}$ tissues including cells, an extracellular matrix (ECM) and a vasculature can be formed. In an alternative approach, in this journal, we have recently shown the combination of cells with engineered cell-adherent micro-objects within a geometrically confined and cell-repellent environment that permits the formation of $3 \mathrm{D}$ tissues through self-assembly. ${ }^{[8]}$ Here, the incorporation of synthetic microscale objects gives increased control over compaction and shape maintenance of the tissue compared to so far biofabricated tissues consisting solely of cells and produced via self-assembly, ${ }^{[9]}$ using magnetic manipulation ${ }^{[10]}$ or acoustic node assembly. ${ }^{[11]}$ However, these exogenous materials also constrain tissue remodeling and organization, and therefore tissues are restricted in naturally developing their tissue architecture.

Advancing on this study, we propose here a purely cell-based bottom-up approach that allows the building of stable tissue constructs with defined complex geometries. We use aggregates of cells as a living, self-scaffolding building block material for the free-form fabrication of complex 3D tissues by sequential self-assembly. To form the building blocks and resulting tissues, we developed a platform based on non-adherent hydrogel templates. This platform is used for high-throughput screening of small molecules and high-content imaging of phenotypical and gene-expression features to fine-tune the physical and biological properties of the building blocks. Adequate building blocks can then be used for the directed assembly, controlled deformation, and development of more complex tissues with unprecedented architectural resolution.

As a platform for the controlled and uniform formation of multicellular building blocks and tissues, we fabricated a microwell array system using soft lithography methods (microwell array, Figure S1A, Supporting Information). Microstructures were copied from a SU-8/silicon wafer via a negative 
replica of the same in the form of an elastomeric stamp cast from poly(dimethylsiloxane) (PDMS) into an agarose hydrogel (Figure S1B and C, Supporting Information). The resulting hydrogel chips including the microstructures were transferred into standard 12-well culture plates (12wp) to maximize compatibility with existing laboratory equipment. A single PDMS stamp was able to imprint arrays of several hundreds to thousands of cylindrical microwells per well of a 12wp and with high precision and reproducibility (Figure S1D, Supporting Information).

As a first step for the sequential assembly of building blocks into tissues, cells were allowed to self-assemble into cellular aggregates within the agarose microwell arrays (Figure 1A). As a second step, these aggregates were used as multicellular building blocks within cavities of millimeter length-scale hydrogel templates with defined geometry, which we termed "geometric arrays." Upon pooling and clustering of the aggregates onto the geometric array (projection area of $1 \mathrm{~mm}^{2}$, height of $750 \mu \mathrm{m}$ ), the building blocks fused into apparent continuous tissues with defined shape within 24 hours (Figure 1A). Upon fusion and culture, the tissues remodeled, deformed, and stabilized their shape (Figure 1A). Adequate culture conditions on the microwell array allowed for the fabrication of tissues with complex stable geometries including, for example, arms of $250 \mu \mathrm{m}$ in length (Figure 1B). The compaction of these tissues occurred in a controlled fashion, in contrast to bioprinting methods where tissues often distort over time. When cells were directly used to form millimeter-scale tissues, dramatic compaction occurred and tissue shape was lost $(p<0.001$, Figure 1C). This emphasized that there is a crucial necessity for fine-tuning the properties of: i) the building blocks, possibly via screening, and ii) the sequential bottom-up approach for the maintenance of the tissue architecture.

Upon continued culture time, circular tissues deformed isotropically, while tissues with sharp edges, for example, triangular tissues, deformed anisotropically, with the greatest displacement in the corners (Figure 1D). These local contractions and deformations resulted in an internal heterogeneity in cellular density (higher cellular density in the periphery as compared to the center, Figure S2, Supporting Information). This initial observation is consistent with the formation of patterns of endogenous mechanical stress induced within tissues by the overall geometry. ${ }^{[12]}$ A combination of Rho/ROCK inhibitor (Y27632, $20 \times 10^{-6} \mathrm{M}$ ) and myosin inhibitor (blebbistatin, $50 \times 10^{-6} \mathrm{M}$ ), stopped tissues from contracting and shifting shape: trifoliumshaped tissues contracted $9 \%$ when treated with a combination of Y27632 and blebbistatin, as compared to 39\% in the untreated control (Figure S3, Supporting Information). This demonstrates that the deformation of tissues is an active biological process driven by the actin-myosin complex. Taking the anisotropy of deformation into account, we designed geometric arrays guiding the tissue to deform toward a desired final geometry such as a square or triangle (Figure 1D). A compensated square geometry led to a tissue that deformed and remodeled into a tissue which overlaps more with a perfect square $(97 \%)$ than an uncompensated, real square geometry $(94 \%$, Figure $1 \mathrm{E}$, for comparison; a perfect circle overlaps $91 \%$ with a perfect square). Interestingly, tissue remodeling can further be manipulated by introducing a shaped constraint inside the geometric array (Figure 1F). The shape and the direction of these inner constraints modulated the outer shape of the tissue, thus adding a supplementary layer of control over deformation. Together, this showed that outer and inner geometries can be designed as such to guide the deformation and form tissues with precise geometries.

The phenotype and function of the assembled tissue are defined by the properties of its building blocks, such as aggregate size, cell type(s), culture (differentiation) medium, and culture time. Fine-tuning these conditions is crucial and allows the properties of the assembled tissue to be modulated. For example, we found that the optimal culture time for aggregates from human mesenchymal stromal cells (hMSCs) to fuse into a continuous tissue while maintaining a final precise square or triangular shape was $5 \mathrm{~d}$ (Figure 1D; Figure S4, Supporting Information). To modulate the size of building blocks, we formed cellular aggregates of hMSCs with controlled diameters ranging from 35 to $150 \mu \mathrm{m}$, depending on the average number of cells per microwell and on the size of the microwells (Figure 2A). Upon aggregation, the diameter of the cellular aggregates increased, decreased, or remained stable over time depending on the culture condition (differentiation media, Figure 2A). For seven different cell types, we classified the stereotypical behaviors into three categories — as "compacting," "growing," or "stable" aggregates-based on their projection area and circularity (Figure S5A, B, and C, respectively, Supporting Information). The time of culture on the microwell array along with the cell type dependent stereotypical behavior strongly influenced and allowed the remodeling of the tissue to be controlled when these aggregates were used as building blocks. As an example, "compacting" spheroids of hMSCs cultured for a longer period of time on the microwell array permitted an increased maintenance of the geometric shape (Figure 2A).

Differentiation media, such as used earlier to steer the cell fate of hMSC aggregates toward the osteogenic, chondrogenic, or adipogenic lineage, contain soluble factors that act on specific genetic circuits within the cells. For example, the small molecule steroid dexamethasone is used to drive cell fate toward the osteogenic lineage. ${ }^{[14]}$ In that regard, functional screening for small chemicals is a valuable method to define conditions that steer stem cell fate and direct the differentiation toward specific cell types. ${ }^{[15]}$ In order to identify novel chemicals modulating the properties of the cellular building blocks, we adapted the microwell array platform to a standard 96-well plate (96wp) format that allows the high-throughput screening (HTS) of small molecules (screening array, Figure S6, Supporting Information). Within each well of a 96wp there are 580 microwells (replicates) reproducibly fabricated with high spatial resolution (Figure S6D, Supporting Information). This conferred compatibility with standard equipment for high-content screening (HCS) and imaging (HCI).

Using this platform, we formed aggregates of mouse embryonic stem cells (mESCs). These mESC aggregates, named embryoid bodies (EBs), formed reproducibly within $24 \mathrm{~h}$ of culture (Figure S7A, Supporting Information). Phenotypical parameters, such as projection area and circularity, were acquired directly on the screening array using bright-field and fluorescence microscopy (Figure S7B, Supporting Information). The variability of the size (projection area) of the EBs was low (Figure S7D, Supporting Information). Circularity never deviated more than 2\% (Figure S7E, Supporting Information). We validated the platform for $\mathrm{HCI}$, using a mESC line combining 
a

Tissue assembly across length scales

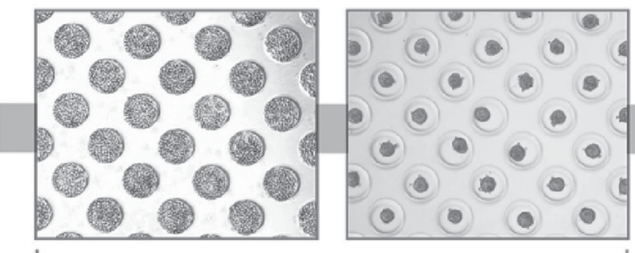

Spheroids $[\approx 100 \mu \mathrm{m}]$ on the microwell array

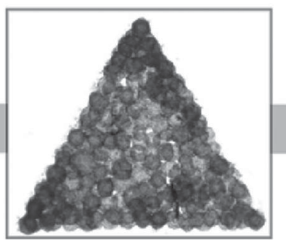

Tissues $[\approx 1000 \mu \mathrm{m}]$ on the geometric array
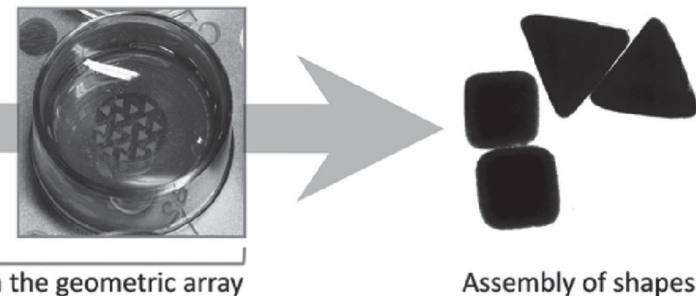

Assembly of shapes

b

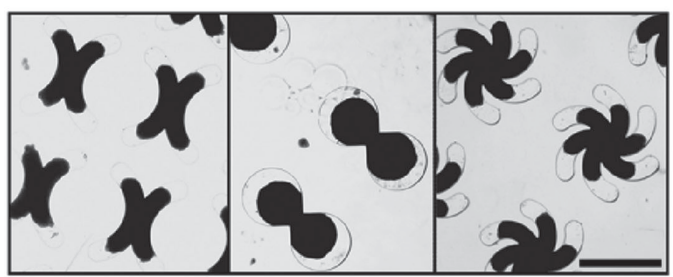

C
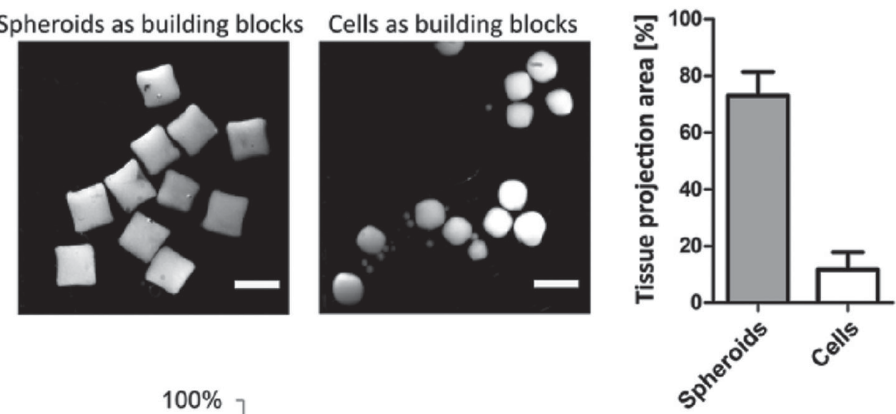

d

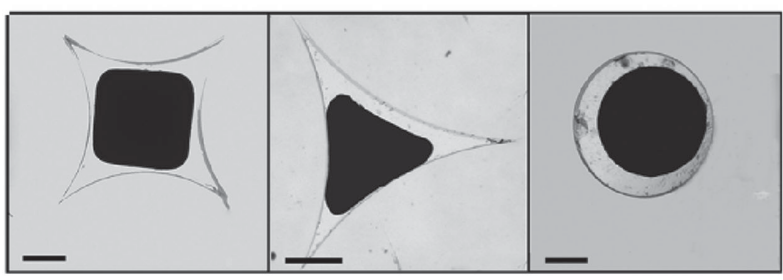

e

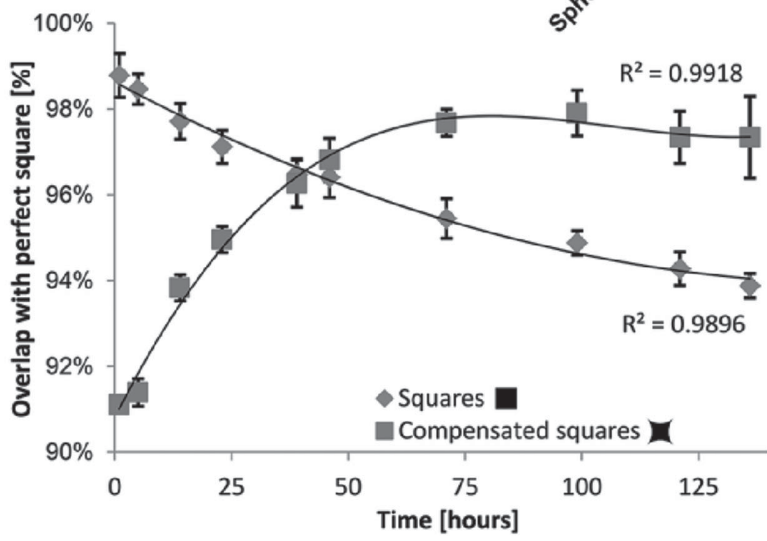

f
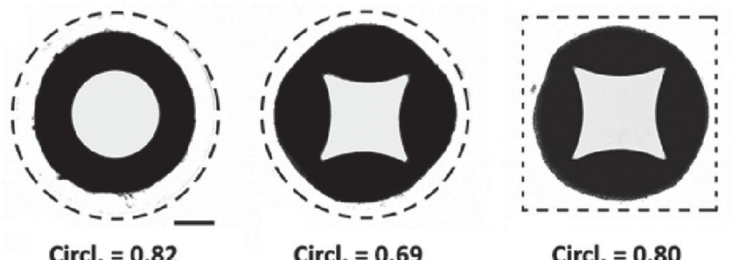

Circl. $=0.80$

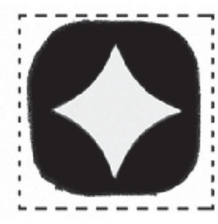

Circl. $=0.63$

Figure 1. Sequential assembly of building blocks into tissues of defined shape. A) Schematic representation of directed tissue assembly across length scales. Cells spontaneously formed building blocks which were then pooled into geometric arrays where they fused into 3D, continuous untethered tissues of defined shape. These shaped tissues were further assembled into larger tissues (see Figure 3). B) Tissues with complex geometries such as curved arms were formed which contracted and stabilized their shape over time (136 h). Scale bar represents $1 \mathrm{~mm}$. C) The preaggregation of cells into spherical building blocks (here, spheroids of hMSCs, cultured for $96 \mathrm{~h}$ ) was essential to form tissues with stable geometries ( $96 \mathrm{~h}$ of culture of geometric arrays). Omitting the intermediate step of spheroid building block formation led to drastic compaction and loss of tissue shape $(n=3$, $p<0.001)$. Scale bar represents $1 \mathrm{~mm}$. D) Tissues contracted autonomously and changed shape anisotropically, with sharp geometric details such as edges and corners inducing a more pronounced deformation and displacement. The anisotropic tissue contraction for square and triangular tissues was controlled by design using templates with compensated geometries. Images depict tissues after $136 \mathrm{~h}$ of culture. Scale bar represents $500 \mu \mathrm{mm}$. E) Compensated geometries correct for the anisotropic contraction of tissues and permit the formation of tissues with predictable geometries. Over time, a well with a compensated square geometry led to a tissue that overlaps more with a perfect square (97\%) than a well with a uncompensated, perfect square geometry ( $94 \%$, for comparison; a perfect circle overlaps $91 \%$ with a real square). F) Tissue remodeling could be further manipulated by introducing shaped constraints inside the geometric array. In circular tissues, a circle-shaped inner constraint did not modulate the outer tissue shape. In contrast, an inner star-shaped constraint changed the outer shape of the circular tissue. In square-shaped tissues, a star-shaped inner constraint better maintained an outer square tissue shape when the constraint was rotated by $45^{\circ}$. Dashed lines represent the outlines of the geometric wells. Scale bar represents $200 \mu \mathrm{m}$. 

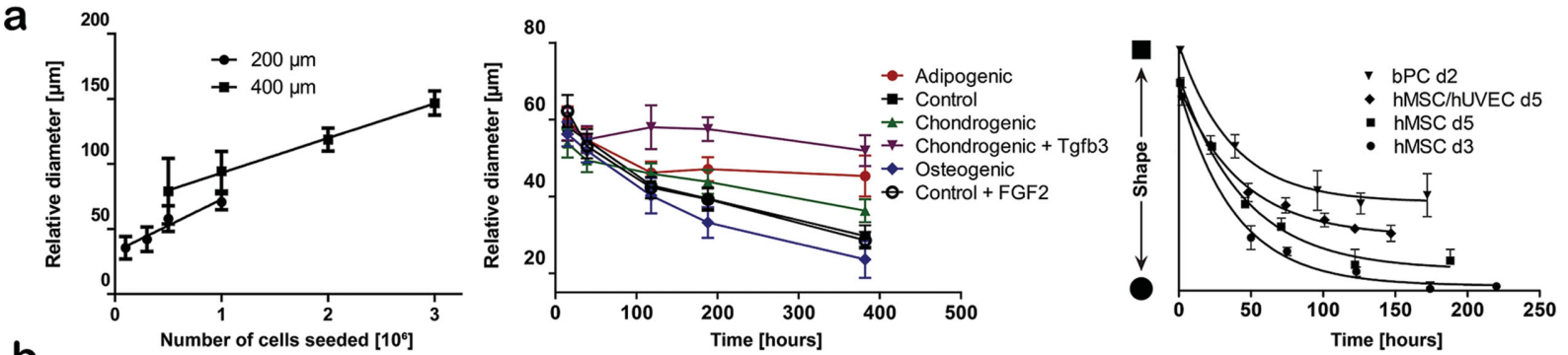

b
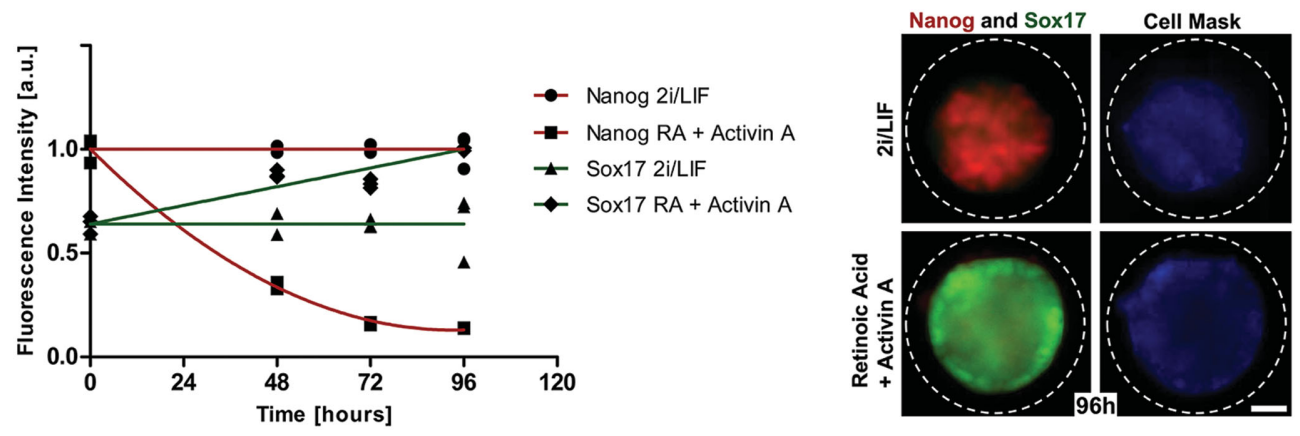

C
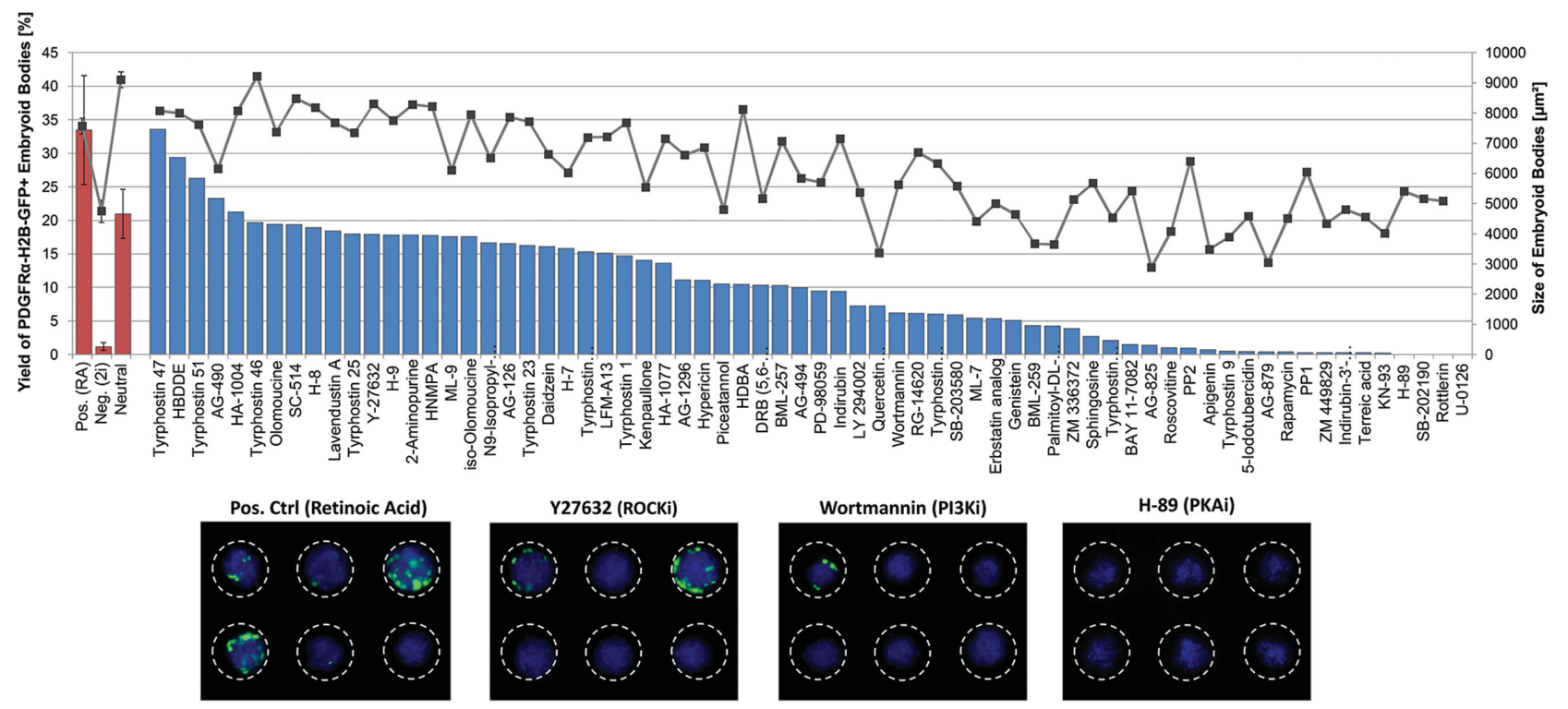

Figure 2. Modulation of building blocks. A) Tuning the properties of building blocks: 1) the relative diameter by adjusting cell number in combination with microwell size, 2) cellular differentiation by defined media, and 3) cell type and culture time define the plasticity of resulting tissue. B) Monitoring differentiation status of building blocks on-chip by fluorescent read-out. Left: the time course of the fluorescent expression of Nanog-RFP and Sox17GFP reporters in mESCs was recorded upon modulation using small molecules. The combination of the small molecules PD0325901 and CHIR99021 with the protein leukemia inhibitory factor (2i/LIF) maintained the high expression of Nanog-RFP and the low expression of Sox $17-G F P$ over 96 h, whereas a combination of retinoic acid and Activin A induced a decrease of Nanog-RFP and an increase in Sox17-GFP. Fluorescence intensity of 15 EBs per well ( $n=3$ wells) was measured and normalized to overall highest and lowest intensity for RFP and GFP, respectively. Right: fluorescence images of representative EBs treated with $2 \mathrm{i} /$ LIF or RA for $96 \mathrm{~h}$. Scale bar represents $25 \mu \mathrm{m}$. C) Using HCS to find chemicals that tune building blocks. A screening using a kinase inhibitor library and a mESC line comprising a Pdgfr $\alpha \mathrm{H} 2 \mathrm{~B}-\mathrm{GFP} /{ }^{+}$reporter identified regulators of the primitive endoderm marker PDGFR $\alpha$. Tyrphostin 47 (EGFr inhibitor, 33\% of EBs positive for H2B-GFP) and U0126 (Mek1/Mek2 inhibitor, 0\% of EBs positive for H2B-GFP) were activators and inhibitors of PDGFR $\alpha$ expression, respectively. The percentage of EBs including GFP+ cells (blue bars) was measured and determined according to $\approx 130 \mathrm{EBs}$ per condition. The projection area of EBs was measured as an approximation for their volume and varied between 2500 and $9500 \mu \mathrm{m}^{2}$. The negative control, a combination of PD325901 and CHIR-99021,[13] led to an average of $1.2 \%$ of EBs that was positive for H2B-GFP expression, $n=6)$. Representative images of six EBs per condition; positive control (RA), and three kinase inhibitors. Scale bar represents $100 \mu \mathrm{m}$.

fluorescent reporters for the promotor activity of the transcription factor Nanog (Nanog-RFP), a gene associated with self-renewal and pluripotency, and a single allele knock-in for Sox17 (Sox17-GFP), a gene involved in the first differentiation steps into primitive endoderm (Figure S8, Supporting Information). ${ }^{[16]}$ The promoter activities of Nanog and Sox17 were modulated by administering small molecules with previously assessed activities on these genes, ${ }^{[17,18]}$ monitored by automated 


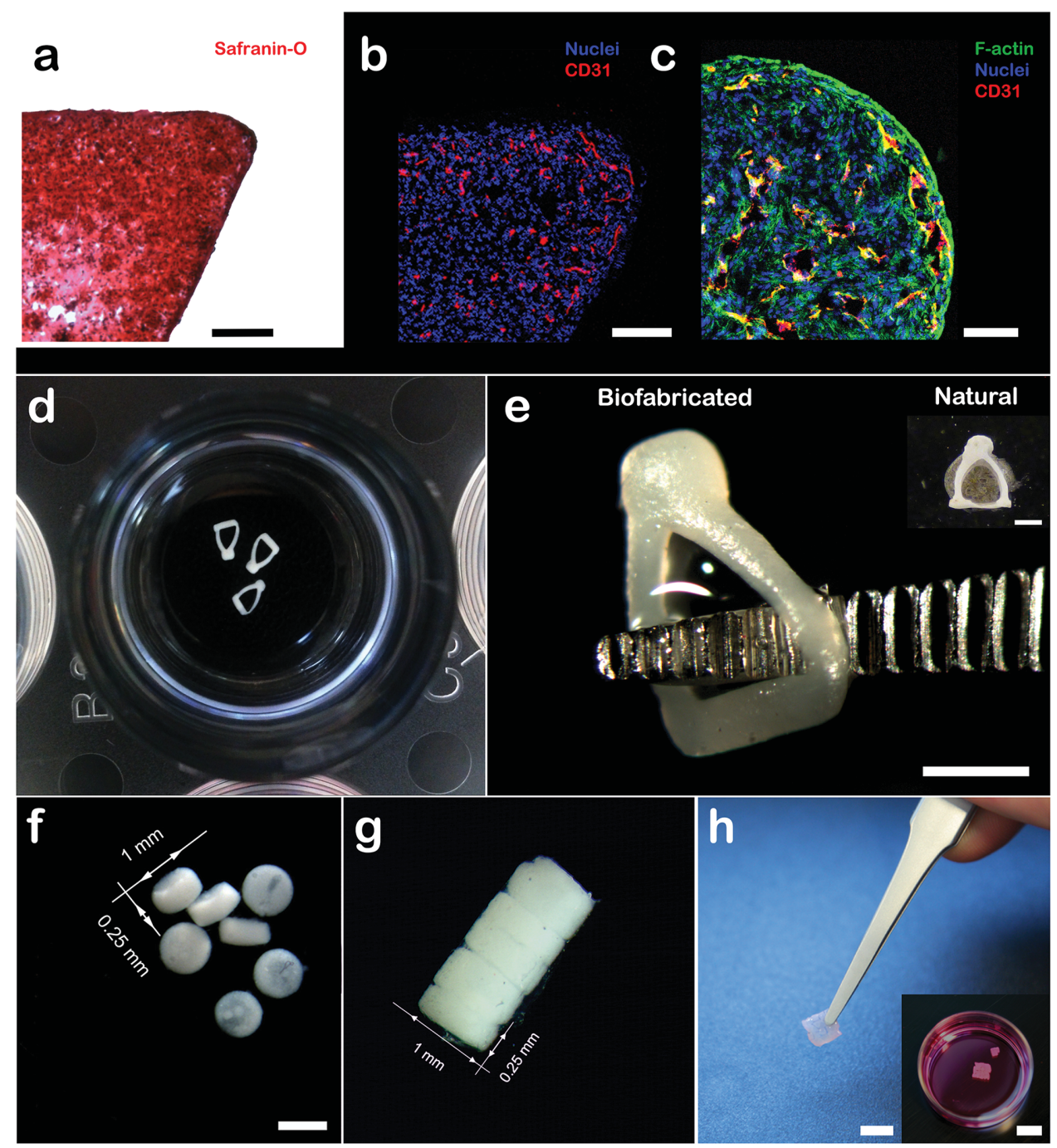

Figure 3. Tissue differentiation, formation, and assembly. A) Self-scaffolding of tissues. Building blocks formed using bovine primary chondrocytes fused into a tissue that produced an extensive ECM (positive for Safranin-O staining) within $21 \mathrm{~d}$. Scale bar represents $200 \mu \mathrm{m}$. B) Pattern formation of primitive vasculature within tissues. Building blocks formed by mixing human mesenchymal stem cells and human umbilical vein endothelial cells fused into a continuous tissue, in which endothelial cells (CD31+) sprouted to form a primitive vasculature within $150 \mathrm{~h}$. Scale bar represents $200 \mu \mathrm{m}$. C) Vasculogenic patterns formed by adding the morphogen Sonic Hedgehog (spherical tissue of $400 \mu \mathrm{m}$ in diameter cultured for $288 \mathrm{~h}$ ). Scale bars represent $50 \mu \mathrm{m}$. D,E) Tissue formed resembling the stapes, a middle-ear bone, with a clinically relevant size and 3D shape, as compared to the natural tissue (image credit: A. Lataster, Dept. of Anatomy \& Embryology, Maastricht University, The Netherlands). Scale bars represent 1 mm. F,G) Millimetersized circular microtissues were assembled and spontaneously fused to form a cylindrical structure. Scale bar represents $1 \mathrm{~mm}$. H) The assembly of square and triangular shaped tissues led, upon fusion, to centimeter-scale, easy-to-handle tissues. Scale bar represents $1 \mathrm{~cm}$.

fluorescence microscopy and quantified. Consistent with studies on the maintenance of pluripotency in mESCs, we show that Nanog-RFP fluorescence intensity was maintained in $2 \mathrm{i} / \mathrm{LIF}$ (GSK3 $\beta$ and MEK/ERK inhibitor, supplemented with leukemia inhibitory factor) and it reproducibly decreased upon exposure to a combination of retinoic acid (RA) and Activin A within $48 \mathrm{~h}$ (Figure 2B). Alternatively, and consistent with studies on the induction of primitive endoderm, Sox17-GFP fluorescence intensity remained stable upon exposure with $2 \mathrm{i} / \mathrm{LIF}$ and increased upon stimulation with RA and Activin A (Figure 2B). Together, these results highlight the sensitivity of the quantification of fluorescent reporter activities as a read-out for the directed differentiation of cellular building blocks.
Then, to demonstrate that a specific building block phenotype can be directed and monitored, we used a kinase inhibitor library to identify kinases involved in the directed differentiation of EBs toward primitive endoderm (Figure 2C). Differentiation was assessed by H2B-GFP reporter activity from a mESC line with a PDGFR $\alpha^{\mathrm{H} 2 \mathrm{~B}-\mathrm{GFP} /+}$ knock-in allele (Figure S8, Supporting Information). ${ }^{[19]}$ As PDGFR $\alpha$ is a plasma membrane-bound receptor, the nuclear translocation of the GFP protein increased the quality of the fluorescent read-out. Differentiation was quantified as the ratio of EBs positive for H2B-GFP compared to the total number of EBs (Figure 2D shows representative images of four compounds with decreasing H2B-GFP expression), and the projection area was averaged over $\approx 300 \mathrm{EBs}$ 
per condition. Consistent with other reports and our previous observation using the Sox17 reporter, the Mek1/Mek2 inhibitors (PD325901 and U0126) were found to inhibit PDGFR $\alpha$ expression. The screen revealed that the protein kinase A (PKA) inhibitor H-89, an ATP-competitive PKA phosphorylation inhibitor, strongly inhibited H2B-GFP expression (0 out of 320 EBs were positive for H2B-GFP expression). Tyrphostin 47 and 51, both epidermal growth factor (EGF) receptor kinase inhibitors, and HBDDE, a protein kinase $\mathrm{C}$ inhibitor, were found to increase the yield of H2B-GFP positive EBs $(3.5,1.5$, and 2.3 standard deviations above the mean of neutral controls, respectively). These results show that small molecule screens can be used to find novel regulators for directed differentiation of 3D tissue building blocks.

Tuning the physical and biological properties of the building blocks by appropriate culture time and medium components appeared a critical step for the formation of stable geometric tissue constructs of millimeter-scale. This balance between remodeling and stability is partly dependent on the balance of cell-cell and cell-matrix interactions. ${ }^{[20]}$ Similar to native tissues in which the ECM acts as an endogenous scaffold that embeds the cells, these tissue constructs should reinforce themselves over prolonged culture time by the secretion of their own ECM. To prove this, shaped tissues from bovine chondrocytes were cultured for 3 weeks and treated with transforming growth factor (TGF) $\beta 3$, which yielded the formation of a continuous Safranin-O positive ECM (Figure 3A; Figure S9, Supporting Information). This result indicates that tissue constructs have the capacity to remodel and stabilize themselves by self-scaffolding, thereby mimicking native tissue architecture. Important in this conjunction is that tissues of increased size should have the capacity to form a vascularized network to overcome the limitations of nutrient and oxygen supply and waste disposal, which might lead to a necrotic core. This is especially important for tissues with high metabolic activity or tissues that develop a less permeable outer shell (e.g., ECM). We and others have previously shown that vascular networks can self-organize in vitro, ${ }^{[21,22]}$ further develop using morphogens (e.g., Sonic Hedgehog) and anastomose with the host's vasculature upon implantation. ${ }^{[21,23]}$ Here, we formed building blocks using a combination of human umbilical vein endothelial cells (hUVECs, positive for CD31) and hMSCs. Upon fusion into a tissue, the hUVECs sprouted and self-organized to form a prevascular network ranging over several hundred micrometers, thus spanning over several building blocks (Figure 3B and Figure S10A, Supporting Information). Moreover, in the presence of the morphogen Sonic hedgehog, the endothelial cells formed lumens resembling blood vessels (Figure 3C; Figure S10B, Supporting Information). Of note, the formation of a necrotic core occurs in certain conditions but can be circumvented by optimizing the culture conditions according to the cell type. The tissues, formed with hMSCs and HUVEC or with chondrocytes, do not exceed $300 \mu \mathrm{m}$ in, at least, one direction, and showed no necrotic core (Figure S11, Supporting Information). Importantly, tissue building blocks retain a degree of plasticity which permits the recapitulation of differentiation and morphogenetic processes, thus allowing novel insights into developmental mechanisms acting at the tissue scale. ${ }^{[1]}$ If cultured for longer time on the microwell array, building blocks can lose their plasticity, which affects the flow of the cells upon fusion and the homogeneity of the final tissue (Figure S4, Supporting Information). Thus, the fine-tuning of the physical and biological properties of the building blocks permits a balance between the desired remodeling required for morphogenesis and the stability of the final geometry.

For therapeutic use, it is highly favored that tissue grafts mimic the native tissue architecture. Here we tested the possibility to assemble tissues that mimic the anatomical shape of the human stapes, which is a small bone in the middle ear, and the smallest bone found in the human body $(\approx 2 \mathrm{~mm}$ $\times 3 \mathrm{~mm}$ in size). Upon assembly of cells and successively of building blocks from these cells, structurally stable tissues were formed with a size and 3D architecture resembling the stapes (Figure 3D,E). The in vitro-fabricated stapes tissues consisted of human cellular material only and were of unprecedented architectural resolution, thus demonstrating the potential of forming precisely defined shapes using cellular building blocks (Figure S12, Supporting Information). The surface and inner properties of the tissues, as investigated using scanning electron microscopy, showed a smooth outer surface and an inner fibrillar structure typical of the extracellular matrix (Figure S13, Supporting Information).

To demonstrate the flexibility to further extend the sequential assembly of tissue constructs, circular shaped tissue modules were assembled into cylindrical tissues (Figure $3 \mathrm{~F}, \mathrm{G}$ ), and square and triangular shaped tissue modules were assembled into a tissue sheet, in a puzzle-like manner (Figure $3 \mathrm{H}$ ). The tissue modules were manually placed within agarose hydrogel confinements and fused within $24 \mathrm{~h}$ to form tissues of centimeter length-scale which were easily handled using surgical instruments, a proof of their self-reinforcing and self-supporting character. We propose these examples of confined self-assembly as a potential means to fabricate tissues with clinical relevance.

The platform allows for the fine-tuning of the physical and biological properties of the building blocks using HTS. This permits the rapid discovery of novel conditions that direct the differentiation of spheroidal building blocks, which can be monitored using HCI. This screening platform differentiates itself from existing methods ${ }^{[7,24]}$ by combining features, such as the high spatial resolution of microwells, high clarity for microscopy, high control over spheroidal building block formation, high replicate number of individual spheroidal building blocks per well of the culture plate, and flexibility in refreshing medium and upscaling potential. In conjunction with fluorescent reporters and live staining methods, this system allows for automated read-out of phenotypical dynamics such as morphogenetic events and gene expression patterns spatially resolved on a cellular level. As such, adequate building blocks can then be used for the directed assembly of tissues in manifold. We envision applicability of this line of fabrication as a replicable method for the production of complex organotypic tissues up to the industrial scale.

The formation of stapes-like tissues demonstrates the dimensional flexibility of the bottom-up approach in building larger tissues with precisely defined shape. To even further improve the geometrical definition of, for example, a biofabricated stapes, a combination of (micro-)CT (X-ray computer tomography) with stereo lithography techniques could be used to build a more accurate $3 \mathrm{D}$ model. We propose that 
this tissue represents an important step toward the formation of fully matured and functional bone tissue via endochondral ossification. These tissues of multi-millimeter or centimeterscale can be easily manipulated using surgical instruments and could potentially serve in clinical applications, for example, by implantation to replace defective tissues or fill a critical defect. As the tissue implant is based on autologous cellular material only, there is increased freedom to integrate into the host tissue. Moreover, potentially unfavorable degradation products from scaffold materials, that might lead to side-effects such as inflammation and fibrous tissue formation, are also avoided. Gas and nutrient exchange can become an issue in such large, dense tissues. Such problems can be circumvented by precise optimization of the building blocks (e.g., metabolic activity), by designing perfusion channels into the final tissue or via the use of bioreactors. Besides clinical applications, tissues of millimeter-scale or larger may provide a means for tissue-scale processes that are difficult to model in vitro, such as tissue fusion for modeling in vivo wound healing.

It is favorable to match the physical properties (stiffness and structure) of tissue constructs to their in vivo counterparts to allow, for example, bone and cartilage tissue replacement. Furthermore, to increase tissue complexity, molded tissues can function as molds themselves. For example, geometric tissues including internal cavities or channels might be fabricated and filled with single cells or spheroidal building blocks. Molded apertures, originating from corresponding pillars in the agarose mold, can also be used to alleviate nutrient deficiencies in tissues of larger size by providing a porous network that enhances diffusion and perfusion, as was studied previously. ${ }^{[25]}$ However, in our approach, and for the aforementioned reasons, we intend to avoid the use of synthetic scaffold materials. To promote neovascularization, endothelial cells can be seeded that line up within these channels. In addition, the resulting tissue assemblies might be cultured on top of a vascular bed. [26]

In conclusion, we demonstrated an accessible and versatile microfabrication platform to build scaffold-free 3D tissues with complex architectures. The novelty of our approach lies in harnessing the power of development, using cells as the only material to build tissues via sequential assembly of multicellular building blocks. This gives tissues the freedom to self-deform, remodel, and become physiologically and functionally more akin to their native analogues.

\section{Experimental Section}

Cell Culture and Reagents: Human bone marrow aspirates were obtained from donors after written informed consent, and hMSCs were isolated and expanded as previously described. ${ }^{[27]}$ During spheroid formation and culture, human mesenchymal stromal cells and bovine primary chondrocytes (bPCs) were cultured in differentiation medium, termed McKay medium, composed of Dulbecco's modified Eagle medium from Life Technologies (LT), supplemented with $10^{-7} \mathrm{M}$ dexamethasone (Sigma), $50 \mathrm{mg} \mathrm{mL}^{-1}$ ascorbate 2-phosphate, $40 \mathrm{mg} \mathrm{mL}^{-1}$ proline, $100 \mathrm{mg} \mathrm{mL}^{-1}$ pyruvate, and $50 \mathrm{mg} \mathrm{mL}^{-1} \mathrm{ITSI}^{+}$ Premix (Becton, Dickinson and Company, MA: $6.25 \mathrm{mg} \mathrm{mL}^{-1}$ insulin, $6.25 \mathrm{mg} \mathrm{mL}^{-1}$ transferrin, $6.25 \mathrm{ng} \mathrm{mL}^{-1}$ selenious acid, $1.25 \mathrm{mg} \mathrm{mL}^{-1}$ bovine serum albumin, $5.35 \mathrm{mg} \mathrm{mL} \mathrm{m}^{-1}$ linoleic acid), $100 \mathrm{U} \mathrm{\textrm {mL } ^ { - 1 }}$ penicillin (LT), and $100 \mathrm{mg} \mathrm{mL}^{-1}$ streptomycin (LT). Differentiation of hMSC derived spheroids and tissues to the adipogenic lineage was done using medium composed of DMEM (Gibco), 10\% FBS

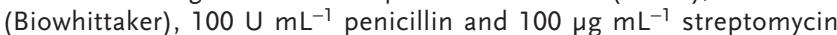
(Gibco), $0.2 \times 10^{-3} \mathrm{M}$ indomethacin (Sigma), $0.5 \times 10^{-3} \mathrm{M} \mathrm{3-isobutyl-}$ 1-methylxanthine (Sigma), $10^{-6} \mathrm{M}$ dexamethasone (Sigma), and $10 \mu \mathrm{g} \mathrm{mL}^{-1}$ insulin (human, Sigma). Differentiation of hMSCs derived spheroids and tissues to the osteogenic lineage was done using basic hMSC medium supplemented with $10^{-8} \mathrm{M}$ dexamethasone (Sigma). Human umbilical vein endothelial cells were purchased from Lonza (Lonza Group Ltd, Switzerland) and cultured in endothelial growth medium-2 (Cambrex). The $\mathrm{C} 2 \mathrm{C} 12$ mouse myoblast, mouse embryonic fibroblast (mEF), and Chinese hamster ovary $(\mathrm{cHO})$ cells were cultured in Dulbecco's modified Eagle medium supplemented with $10 \%$ fetal bovine serum (FBS) (LT), $100 \mathrm{U} \mathrm{mL}^{-1}$ penicillin (LT) and $100 \mathrm{mg} \mathrm{mL}^{-1}$ streptomycin (LT). Mouse embryonic stem cells were expanded on $\mathrm{mEF}$ cells in ES medium consisting of: Dulbecco's modified Eagle medium high glucose (LT) supplemented with $10 \%$ fetal bovine serum (FBS) (Greiner), $4 \times 10^{-3} \mathrm{M}$ Glutamax

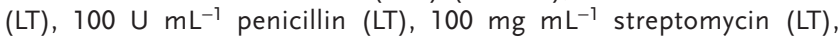
$10 \times 10^{-3} \mathrm{M}$ nonessential amino acids (LT), freshly supplemented with $0.05 \times 10^{-3} \mathrm{M}$ 2-mercaptoethanol (LT), $1000 \mathrm{U} \mathrm{mL}^{-1}$ leukemia inhibitory factor (LT), $3 \times 10^{-6} \mathrm{M}$ CHIR99021 (CSK3 $\beta$ inhibitor, Axon Medchem) and $1 \times 10^{-6} \mathrm{M}$ PD0325901 (MEK/ERK inhibitor, Sigma Aldrich).

Tissue Culture: Building blocks were flushed out of the microwells after appropriate culture time, collected by centrifugation, resuspended in fresh McKay medium and seeded onto the geometric array at a density of 300 to 500 building blocks per tissue with a PA of $1 \mathrm{~mm}^{2}$. Medium was refreshed every $2 \mathrm{~d}$. Tissues with primitive vascular structures were formed by culturing spheroids, consisting of a mixed population of $92 \%$ hMSCs and $8 \%$ hUVECs, for $5 \mathrm{~d}$ on the microwell array and $150 \mathrm{~h}$ on the compensated triangle-shaped geometric array. bPCs were cultured for $2 \mathrm{~d}$ on the microwell array and then cultured on the geometric arrays (triangle, square, circle) for $21 \mathrm{~d}$ in differentiation medium (McKay) supplemented with transforming growth factor $\beta 3$ (TGF $\beta 3,10 \mathrm{ng} \mathrm{mL}^{-1}$ ). Stapes-shaped tissues were formed using human primary chondrocytes expanded in hypoxic conditions $\left(2.5 \% \mathrm{O}_{2}\right)$. Spheroids were formed on the microwell array (140 cells/ spheroid, 2800 spheroids per microwell array chip) and cultured for $48 \mathrm{~h}$. Then, spheroids from 8 chips $(\approx 22000$ spheroids) were seeded onto the stapes geometric array, yielding five stapes tissues which were fixated using $4 \% \mathrm{w} / \mathrm{v}$ paraformaldehyde after $72 \mathrm{~h}$. Spheroids and stapes tissues were cultured in McKay medium including $10 \mathrm{ng} \mathrm{mL}^{-1}$ TGFb3 and refreshed every $2 \mathrm{~d}$.

Kinase Inhibitor Screening: The kinase inhibitor library V2.2 $(80$ chemicals reconstituted at $10 \times 10^{-3} \mathrm{M}$ in DMSO) from Enzo Life Sciences was used to screen for compounds that modulate H2B-GFP reporter activity in EBs from a mouse embryonic stem cell line comprising a PDGFR $\alpha^{\mathrm{H} 2 \mathrm{~B}-\mathrm{gfp} /+}$ knock-in allele (a histone H2B-GFP fusion protein reporter under the control of PDGFR $\alpha$ regulatory elements ${ }^{[19]}$ ). In each well, we aimed to seed 5590 cells, which equates to an average of 13 cells per microwell, and allowed to aggregate over $24 \mathrm{~h}$ in $250 \mu \mathrm{L}$ well ${ }^{-1}$ of ES-medium supplemented with $1 \mu \mathrm{g} \mathrm{mL}^{-1} \mathrm{LIF}$ and $50 \times 10^{-6} \mathrm{M}$ $\beta$-mercaptoethanol. After $24 \mathrm{~h}, 200 \mu \mathrm{L}$ of medium was refreshed with ES-medium supplemented with $50 \times 10^{-6} \mathrm{M} \beta$-mercaptoethanol and the kinase inhibitor drugs were administered in a working concentration of $20 \times 10^{-6} \mathrm{M}$. After $72 \mathrm{~h}, 100 \mu \mathrm{L}$ of medium was refreshed with ES-medium supplemented with $50 \times 10^{-6} \mathrm{M} \beta$-mercaptoethanol, and the kinase inhibitor drugs were administered again at a concentration of $20 \times 10^{-6} \mathrm{M}$. RA was used as a positive control for H2B-GFP expression. ${ }^{[18]}$ After $96 \mathrm{~h}$, the EBs were fixated in 4\% paraformaldehyde, washed thoroughly in PBS, stained with $0.7 \mu \mathrm{g} \mathrm{mL} \mathrm{m}^{-1}$ DAPI solution (Sigma Aldrich, D9542), washed thoroughly in PBS and imaged using the image-montage function and a 10x objective on the BD Pathway 435. Phenotypic data were acquired from montaged images using a custom-made pipeline in CellProfiler2.0 (Broad Institute; ref. [28]). The yield of EBs with cells positive for PDGFR $\alpha$-H2B-GFP was determined using an intensity threshold on $\approx 130$ EBs per condition (i.e., per well). Compounds that were autofluorescent or images that were not in focus were omitted of analysis ( 13 out of 96 conditions). 
Immunohistochemical Analysis: After harvesting, tissues were frozen in Cryomatrix at $-60{ }^{\circ} \mathrm{C}$. Sections $(7 \mu \mathrm{m})$ were prepared on a cryotome. Sections were fixed in cold acetone for $5 \mathrm{~min}$, air-dried, and rehydrated for 10 min, after which they were incubated for 30 min with 10\% FBS in PBS to block nonspecific background staining. Sections were incubated with monoclonal mouse anti-human CD31 antibody (Dako, 1:20) for $1 \mathrm{~h}$. Sections were washed in PBS and incubated with the secondary antibody (Alexa Fluor 488, Invitrogen). Samples were counterstained with DAPI. Pictures were acquired on an inverted confocal microscope (Leica LSM500). Cartilage formation was assessed by Safranin-O staining according to standard protocols.

\section{Supporting Information}

Supporting Information is available from the Wiley Online Library or from the author.

\section{Acknowledgements}

The authors gratefully acknowledge the Dutch Institute for Regenerative Medicine (NIRM) for funding of this project. N.R. thanks the ZonMW program for translational adult stem cells. The authors declare there is no conflict of interest. The authors would like to thank Sean Morrison for providing the Sox17GFP/+ embryonic stem cell line and Anna-Katerina Hadjantonakis for providing the PDGFR $\alpha \mathrm{H} 2 \mathrm{~B}-\mathrm{GFP} /+$ embryonic stem cell line. N.R. initiated and led the project. E.V., J.R., R.T., and N.R. designed the experiments. E.V. and N.R. conducted the experiments. E.V., J.R., and N.R. analyzed data. E.V., J.R., V.L., R.T., and N.R. wrote the manuscript. All authors discussed the results and commented on the manuscript. N.R., J.R., E.V., R.T., and C.V.B. were granted the patent "Self-assembling tissue modules" describing this technology.

Received: November 18, 2015 Revised: January 19, 2016 Published online: March 22, 2016

[1] N. C. Rivron, E. J. Vrij, J. Rouwkema, S. Le Gac, A. van den Berg, R. K. Truckenmuller, C. A. van Blitterswijk, Proc. Natl. Acad. Sci. USA 2012, 109, 6886.

[2] a) A. Ranga, S. Gobaa, Y. Okawa, K. Mosiewicz, A. Negro, M. P. Lutolf, Nat. Commun. 2014, 5, 4324; b) S. Allazetta, L. Kolb, S. Zerbib, J. Bardy, M. P. Lutolf, Small 2015, 11, 5647; C) K. A. Mosiewicz, L. Kolb, A. J. van der Vlies, M. M. Martino, P. S. Lienemann, J. A. Hubbell, M. Ehrbar, M. P. Lutolf, Nat. Mater. 2013, 12, 1072

[3] a) C. M. Nelson, R. P. Jean, J. L. Tan, W. F. Liu, N. J. Sniadecki, A. A. Spector, C. S. Chen, Proc. Natl. Acad. Sci. USA 2005, 102, 11594; b) J. M. Kelm, L. M. Ittner, W. Born, V. Djonov, M. Fussenegger, J. Biotechnol. 2006, 121, 86; c) C. M. Nelson, M. J. Bissell, Annu. Rev. Cell Develop. Biol. 2006, 22, 287.

[4] a) J. W. Nichol, A. Khademhosseini, Soft Matter 2009, 5, 1312; b) J. S. Liu, Z. J. Gartner, Trends Cell Biol. 2012, 22, 683.

[5] S. Guven, P. Chen, F. Inci, S. Tasoglu, B. Erkmen, U. Demirci, Trends Biotechnol. 2015, 33, 269.

[6] a) K. Pataky, T. Braschler, A. Negro, P. Renaud, M. P. Lutolf, J. Brugger, Adv. Mater. 2012, 24, 391; b) D. B. Kolesky, R. L. Truby, A. S. Gladman, T. A. Busbee, K. A. Homan, J. A. Lewis, Adv. Mater. 2014, 26, 3124; c) F. Pati, J. Jang, D. H. Ha, S. Won Kim, J. W. Rhie, J. H. Shim, D. H. Kim, D. W. Cho, Nat. Commun. 2014, 5, 3935; d) U. A. Gurkan, R. El Assal, S. E. Yildiz, Y. Sung, A. J. Trachtenberg, W. P. Kuo, U. Demirci, Mol. Pharm. 2014, 11, 2151.

[7] K. R. Stevens, M. D. Ungrin, R. E. Schwartz, S. Ng, B. Carvalho, K. S. Christine, R. R. Chaturvedi, C. Y. Li, P. W. Zandstra, C. S. Chen, S. N. Bhatia, Nat. Commun. 2013, 4, 1847.
[8] A. Leferink, D. Schipper, E. Arts, E. Vrij, N. Rivron, M. Karperien, K. Mittmann, C. van Blitterswijk, L. Moroni, R. Truckenmuller, Adv. Mater. 2014, 26, 2592.

[9] a) A. P. Napolitano, D. M. Dean, A. J. Man, J. Youssef, D. N. Ho, A. P. Rago, M. P. Lech, J. R. Morgan, BioTechniques 2007, 43, 494; b) A. P. Rago, D. M. Dean, J. R. Morgan, Biotechnol. Bioeng. 2009, 102, 1231.

[10] A. M. Bratt-Leal, K. L. Kepple, R. L. Carpenedo, M. T. Cooke, T. C. McDevitt, Integr. Biol. 2011, 3, 1224.

[11] P. Chen, S. Guven, O. B. Usta, M. L. Yarmush, U. Demirci, Adv. Healthcare Mater. 2015, 4, 1937.

[12] N. Gjorevski, E. Boghaert, C. M. Nelson, Cancer Microenviron. 2012 5, 29.

[13] a) J. Nichols, J. Silva, M. Roode, A. Smith, Development 2009, 136, 3215; b) Y. Yamanaka, F. Lanner, J. Rossant, Development 2010, 137, 715.

[14] S. L. Cheng, J. W. Yang, L. Rifas, S. F. Zhang, L. V. Avioli, Endocrinology 1994, 134, 277.

[15] a) D. E. Cohen, D. Melton, Nat. Rev. Genet. 2011, 12, 243; b) W. Li, K. Jiang, W. Wei, Y. Shi, S. Ding, Cell Res. 2013, 23, 81.

[16] J. Artus, A. Piliszek, A. K. Hadjantonakis, Develop. Biol. 2011, 350, 393.

[17] a) Q. L. Ying, J. Wray, J. Nichols, L. Batlle-Morera, B. Doble, J. Woodgett, P. Cohen, A. Smith, Nature 2008, 453, 519; b) L. T. Cho, S. E. Wamaitha, I. J. Tsai, J. Artus, R. I. Sherwood, R. A. Pedersen, A. K. Hadjantonakis, K. K. Niakan, Development 2012, 139, 2866.

[18] M. P. Stavridis, B. J. Collins, K. G. Storey, Development 2010, 137, 881.

[19] B. Plusa, A. Piliszek, S. Frankenberg, J. Artus, A. K. Hadjantonakis, Development 2008, 135, 3081.

[20] K. Jakab, A. Neagu, V. Mironov, R. R. Markwald, G. Forgacs, Proc. Natl. Acad. Sci. USA 2004, 101, 2864.

[21] S. Levenberg, J. Rouwkema, M. Macdonald, E. S. Garfein, D. S. Kohane, D. C. Darland, R. Marini, C. A. van Blitterswijk, R. C. Mulligan, P. A. D'Amore, R. Langer, Nat. Biotechnol. 2005, 23, 879.

[22] J. Rouwkema, J. de Boer, C. A. Van Blitterswijk, Tissue Eng. 2006, 12, 2685.

[23] a) J. Rouwkema, N. C. Rivron, C. A. van Blitterswijk, Trends Biotechnol. 2008, 26, 434; b) N. C. Rivron, C. C. Raiss, J. Liu, A. Nandakumar, C. Sticht, N. Gretz, R. Truckenmuller, J. Rouwkema, C. A. van Blitterswijk, Proc. Natl. Acad. Sci. USA 2012, 109, 4413.

[24] a) Y. C. Tung, A. Y. Hsiao, S. G. Allen, Y. S. Torisawa, M. Ho, S. Takayama, Analyst 2011, 136, 473; b) E. Gottwald, S. Giselbrecht, C. Augspurger, B. Lahni, N. Dambrowsky, R. Truckenmuller, V. Piotter, T. Gietzelt, O. Wendt, W. Pfleging, A. Welle, A. Rolletschek, A. M. Wobus, K. F. Weibezahn, Lab Chip 2007, 7, 777; c) A. Sridhar, H. L. de Boer, A. van den Berg, S. Le Gac, PLoS One 2014, 9, e93618; d) B. Altmann, R. Ahrens, A. Welle, H. Dinglreiter, M. Schneider, A. Schober, Biomed. Microdevices 2012, 14, 291; e) B. R. Desroches, P. Zhang, B. R. Choi, M. E. King, A. E. Maldonado, W. Li, A. Rago, G. Liu, N. Nath, K. M. Hartmann, B. Yang, G. Koren, J. R. Morgan, U. Mende, Am. J. Physiol. Heart Circ. Physiol. 2012, 302, H2031.

[25] X. Ye, L. Lu, M. E. Kolewe, K. Hearon, K. M. Fischer, J. Coppeta, L. E. Freed, Adv. Mater. 2014, 26, 7202.

[26] H. Sekine, T. Shimizu, K. Sakaguchi, I. Dobashi, M. Wada, M. Yamato, E. Kobayashi, M. Umezu, T. Okano, Nat. Commun. 2013, 4, 1399

[27] R. Siddappa, A. Martens, J. Doorn, A. Leusink, C. Olivo, R. Licht, L. van Rijn, C. Gaspar, R. Fodde, F. Janssen, C. van Blitterswijk, J. de Boer, Proc. Natl. Acad. Sci. USA 2008, 105, 7281.

[28] M. R. Lamprecht, D. M. Sabatini, A. E. Carpenter, BioTechniques 2007, 42, 71. 